www.jmscr.igmpublication.org

Impact Factor 5.84

Index Copernicus Value: 83.27

ISSN (e)-2347-176x ISSN (p) 2455-0450

crossref DOI: _https://dx.doi.org/10.18535/jmscr/v5i8.44

Journal Of Medical Science And Clinical Research

\title{
The BODE Index and Health Related Quality of Life-Is there a correlation in COPD?
}

\author{
Authors \\ Venugopal K.P ${ }^{1}$, Thomas George $P^{2}$, Kiran $V N^{3}$, Jain $G^{4}$ \\ ${ }^{1}$ Associate Professor, ${ }^{2}$ Professor and Head, ${ }^{3}$ Assistant Professor, ${ }^{4}$ Junior Resident, \\ Department of Pulmonary Medicine, Government Medical College, Kottayam, Kerala, India \\ Corresponding Author \\ Thomas George.P \\ Email:tomeegeo@gmail.com
}

\begin{abstract}
Context: COPD a progressive respiratory disease, leads to permanent disability \& a negative impact on the quality of life. BODE index , a multidimensional index provides prognostic information in COPD patients but it is not known whether it can be used as a sensitive tool for predicting the Health related quality of life(HRQoL). HRQoL is assessed using the St George Respiratory Questionnaire validated for the Indian population.
\end{abstract}

Aims: To Study correlation between BODE Index and HRQoL among stable COPD Patients.

Settings and Design: Cross sectional study conducted in a tertiary care center with a Pulmonology Outpatient department.

Methods and Material: The study was conducted among 50 stable COPD patients aged above 40 years for 12 months. The BODE index score and HRQoL were measured.

Statistical analysis used: A Spearman's $(\rho)$ \&Pearson's correlation coefficient ( $r)$ analysis were done to find out the correlation between different variables

Results: The BODE index was categorized into quartiles:0-2,3-4,5-6\&7-10.Mean total SGRQ scores and scores of individual components of the SGRQ increased with the increase in BODE index quartiles. Strong correlation ( $\rho=0.922 ; p<0.001)$ were found between baseline mean total SGRQ scores and BODE quartiles. When the individual components of BODE index were assessed, FEV1 \% predicted and 6MWD had negative correlations and mMRC dyspnea grades had a positive correlation with the total SGRQ score. A lower BMI ( $\leq 21)$ was associated with higher total $S G R Q$ score and vice versa.

Conclusion: Higher BODE quartiles were associated with higher SGRQ scores (worse health status). BMI and $6 M W D$ showed a significant correlation with health related quality of life.

Key-words: $C O P D, B O D E, S G R Q, H R Q o L$

Key messages: Lung function and exacerbation frequencies incorporated in GOLD guidelines for therapy decisions and prognostication ignores the Quality of life experienced by a patient. Multidimensional indices like BODE correlate well with health status assessed by the St George Respiratory Questionnaire and should be incorporated in future COPD guidelines. 


\section{Introduction}

Chronic obstructive pulmonary disease (COPD) epitomised by persistent and progressive airflow limitation is characterized by progressive deterioration of respiratory function over time and systemic effects which have a great impact on health-related quality of life (HRQoL). The major manifestation of airflow obstruction in COPD is a reduction in forced expiratory volume in first second $\left(\mathrm{FEV}_{1}\right)$. This forms the basis of the classification of COPD severity by the Global initiative for Chronic obstructive lung disease (GOLD) ${ }^{1}$. The evaluation of lung function by FEV 1 alone, though fails to represent the complex clinical consequences of COPD ${ }^{2} . \mathrm{FEV}_{1}$ as an individual measure also correlates poorly with patients symptoms, quality of life, exacerbation frequency and exercise intolerance ${ }^{4,5}$. BODE index, a multidimensional parameter proposed by Celli et $\mathrm{al}^{3}$ in COPD, was reported to be superior to $\mathrm{FEV}_{1}$ in reflecting the severity and predicting mortality of patients. Improving patients symptoms, functional status, and quality of life are important goals in the management of COPD and can be assessed using standardised questionnaires like the St George Respiratory Questionnaire (SGRQ) ${ }^{6}$. This study aims to know if BODE index can objectively correlate the HRQoL in stable COPD patients

\section{Objective}

To Study the Correlation between BODE Index with Health Related Quality of Life Among stable COPD Patients,

\section{Subjects and Methods}

A cross sectional study was conducted in 50 consecutive stable COPD patients attending the out-patient department of Pulmonary medicine from August 2015 to August 2016. Stable patients aged $>40$ years diagnosed as per ATS/ERS recommendations of Post bronchodilator (Post BD) $\mathrm{FEV}_{1} / \mathrm{FVC}$ of $<.7$ using a COSMED spirometer were included. Those with other coexisting pulmonary diseases like
Bronchiectasis, Past Pulmonary Tuberculosis, Obstructive sleep apnoea, Asthma COPD overlap, Interstitial Lung diseases, Severe Pulmonary Hypertension and unable to do a Six Minute Walk Test(6MWT) and Spirometry were excluded.

After getting an informed consent, a detailed history and thorough physical examination were done in all patients. Body mass index (BMI) was calculated as Weight in Kilograms upon (Height in metres). The distance walked in a 6MWT and Post BD $\mathrm{FEV}_{1}$ percentage predicted values were noted in all patients. Severity of dyspnoea was assessed by the modified Medical Research Council (mMRC) dyspnoea grades. BODE index score was calculated by summation of scores obtained for each variable (BMI, Post BD FEV 1 $\%$, mMRC dyspnoea and 6 min walk distance (6MWD)). The BODE score was divided into quartiles as follows: quartile 1 (a score of 0 to 2 points), quartile 2 (3 to 4 points), quartile 3 (5 to 6 points), and quartile 4 (7 to 10 points), higher quartiles indicating severe forms of COPD. Health related quality of life was measured using the English and vernacular versions of SGRQ validated to be used in the Indian population. The SGRQ is a fifty item questionnaire developed to measure health status in patients with obstructive airway diseases. Three domains were scored namely symptoms, activity, impact and a total score was generated. Randomised controlled trials have demonstrated sensitivity, repeatability, reliability and validity of this questionnaire in assessing Quality of Life in obstructive airway diseases.

Statistical analysis was carried out using SPSS 17 Data and were expressed as mean \pm Standard Deviation(SD). A Spearman's $(\rho)$ correlation coefficient (r) analysis was done to find out the correlation between different variables.

\section{Results}

A total of 50 patients were included in the study. The mean age was $61.4 \pm 7.3$ years, and majority of 
the study population (88\%) were males as shown in Table 1 and Figure 1 respectively.

Table 1 showing age distribution

\begin{tabular}{|l|c|c|}
\hline Age group & Frequency & Percent \\
\hline $45-60$ & 23 & 46.0 \\
\hline$>60$ years & 27 & 54.0 \\
\hline Total & 50 & 100.0 \\
\hline
\end{tabular}

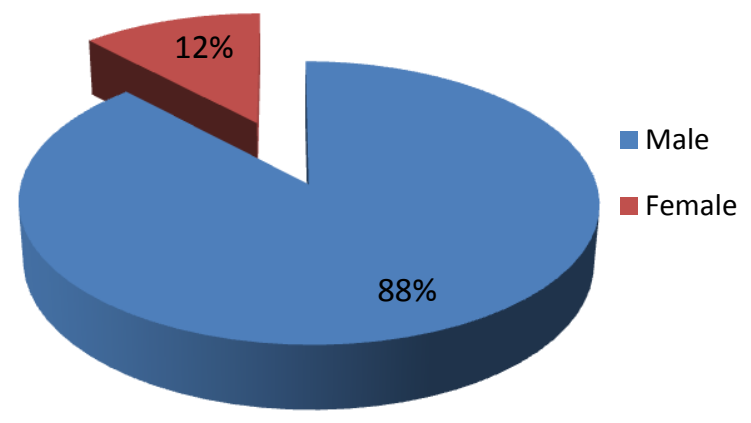

Figure 1 showing the sex distribution Of the 50 patients, $43(86 \%)$ were smokers and 34 people among these had a pack year of 20-40 and 9 had less than twenty pack years. The mean pack years were $21.89 \pm 10.33 .7$ people were non smokers. Assessment of BMI in the 50 patients showed a minimum value of 17 and a maximum of 23.9 with a mean BMI of $21.08 \pm 1.33$ $\mathrm{kg} / \mathrm{m} 2$.The BMI was classified into two groups as per the BODE scoring as shown in Table 2.

Table 2 showing Body Mass Index

\begin{tabular}{|l|c|c|}
\hline BMI & Frequency & Percent \\
\hline$\leq 21$ & 21 & 42.0 \\
\hline$>21$ & 29 & 58.0 \\
\hline Total & 50 & 100.0 \\
\hline
\end{tabular}

The mean post BD FEV1\% predicted value of the study population was $55.87 \pm 10.67$. We classified the values of post BD FEV1\% as per the GOLD 2016 guidelines. $68 \%$ of our study population belonged to stage 2, 26\% stage 3,4\% stage 1 and $2 \%$ to stage 4 .We also segregated them based on their gender into different groups as seen in the Table 3.
Table 3 showing the FEV1 staging as per GOLD criteria

\begin{tabular}{|l|c|c|c|c|}
\hline Stages & Male $(\mathrm{n})$ & Female $(\mathrm{n})$ & Total $(\mathrm{n})$ & Percent \\
\hline GOLD 1 & 2 & 0 & 2 & 4.0 \\
\hline GOLD 2 & 30 & 4 & 34 & 68.0 \\
\hline GOLD 3 & 12 & 1 & 13 & 26.0 \\
\hline GOLD 4 & 0 & 1 & 1 & 2.0 \\
\hline Total & 44 & 6 & 50 & 100.0 \\
\hline
\end{tabular}

As mentioned, we had categorized the calculated BODE scores for the subjects into quartiles:0-2, 3$4,5-6 \& 7-10.22 \%$ of the study population were in BODE $1^{\text {st }}$ quartile, $30 \%$ were in $2^{\text {nd }}$ quartile, $34 \%$ were in $3^{\text {rd }}$ quartile and $14 \%$ were in the $4^{\text {th }}$ quartile(Figure 2).

Figure 2: BODE quartiles among study population

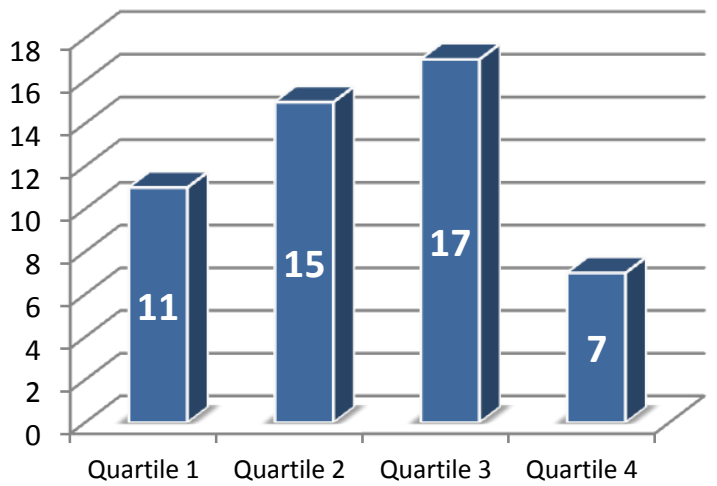

The mean 6MWD in the study population was $233.2 \pm 69.37 \mathrm{~m}$ and the mean SGRQ scores were as follows-Symptom 53.03, activity 56.74, impact 37.32 and a total score of $45.18 \pm 18.4$. Subsequently we correlated the BODE quartiles with individual and mean SGRQ scores as seen in the following table 4

Table 4 : Distribution of SGRQ scores according to BODE Quartiles(SD- Standard Deviation)

\begin{tabular}{llc|c|c|c}
\hline BODE quartiles & Symptom & Activity & Impact & SGRQscore \\
Quartile 1 & Mean & 27.27 & 36.64 & 14.20 & 22.12 \\
& SD & 7.37 & 4.87 & 5.96 & 5.34 \\
\hline Quartile 2 & Mean & 48.480 & 48.97 & 28.69 & 37.36 \\
\cline { 2 - 6 } & SD & 6.61 & 3.91 & 5.50 & 4.59 \\
\hline Quartile 3 & Mean & 64.26 & 61.66 & 47.19 & 54.27 \\
\cline { 2 - 6 } & SD & 6.85 & 14.14 & 8.88 & 8.26 \\
Quartile 4 & Mean & 75.95 & 93.00 & 68.21 & 76.11 \\
& SD & 2.37 & 3.43 & 3.05 & 3.22 \\
\hline Total & Mean & 53.03 & 56.74 & 37.33 & 45.18 \\
\hline & SD & 17.71 & 19.53 & 1.88 & 18.41 \\
\hline $\begin{array}{l}\text { Spearman's } \\
\text { rho }\end{array}$ & & 937 & .881 & .928 & 922 \\
p valve & & $<.001$ & $<.001$ & $<.001$ & $<.001$
\end{tabular}


The mean total SGRQ scores and the individual parts of the SGRQ scores of symptom, activity and impact showed a statistically significant increase with incremental BODE quartiles. A strong correlation was found between BODE index quartiles and SGRQ scores. A pictorial line graph depicting BODE quartiles with individual scores of the SGRQ is shown in Figure 3. The numerical values of individual components of SGRQ as well as the mean total SGRQ scores increased with decrease in Post BD FEV1\%, but showed only a moderate correlation $(\rho=.565$, $\mathrm{p}<0.01)$.Significant correlation was found in 6MWD and mMRC grades for both mean SGRQ scores and individual component of SGRQ score. So higher mMRC grades and lower 6MWD were associated with a lower SGRQ score. Lower BMI $(\leq 21)$ was also associated with a higher total SGRQ score and higher BMI (>21)was associated with lower total SGRQ scores as seen in Table 5.

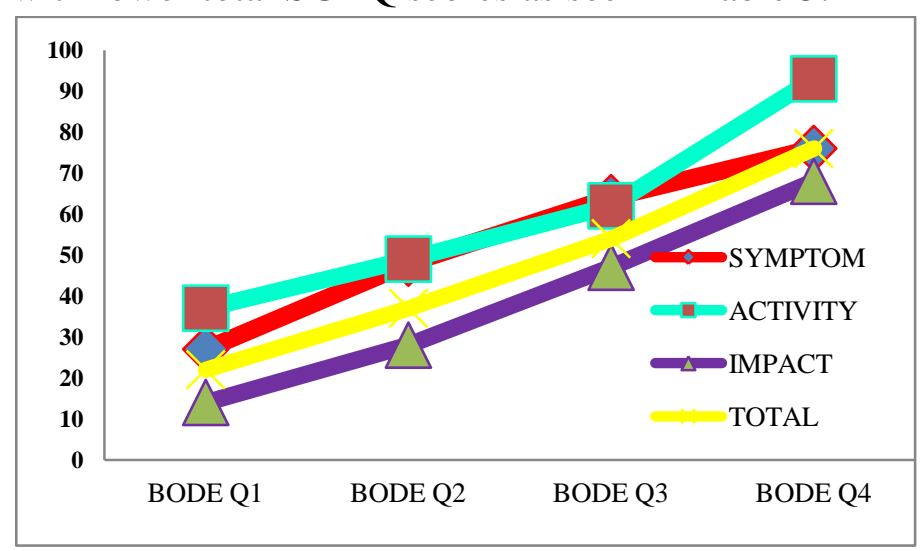

Figure 3 : Correlation between BODE quartiles and SGRQ score

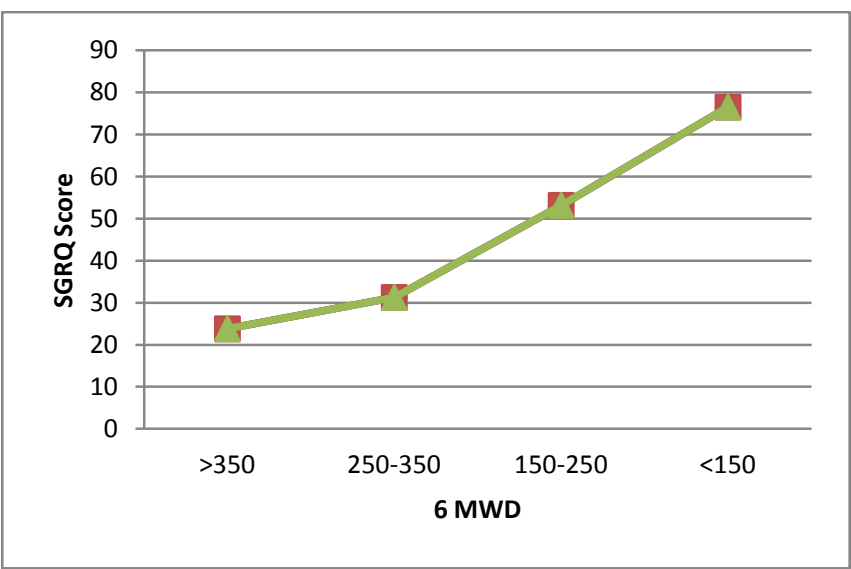

Figure 4: 6 minute walk distance and mean SGRQ scores

\section{Discussion}

This study was conducted to find out the correlation between BODE index and health related quality of life as assessed by SGRQ score. Mean SGRQ score of the study population was $45.18(\mathrm{SD}=18.41)$, with symptom domain mean of 53,03 ( $\mathrm{SD}=17.71)$, activity domain mean of $56.74(\mathrm{SD}=19.53)$ and impact domain mean of37.33 ( $\mathrm{SD}=18.86)$. There is no statistically significant association between gender and SGRQ scores.

Previous studies regarding the correlation between FEV1 and SGRQ score found that FEV1 $\%$ is poorly or not at all correlated with SGRQ score ${ }^{7}$. FEV1 is not identified as a predictor of health-related quality of life in COPD patient. Antonelli-Incalzi et al. in their study found that the GOLD staging of COPD corresponded to important differences in health status between stages II and III, but not between other consecutive stages, and the authors concluded that crossing the boundary of a FEV1 of $<50 \%$ of predicted was a dramatic decline in health status ${ }^{8}$. In this study found that GOLD classes had modest correlation with baseline SGRQ score $(\mathrm{P}=.565, \mathrm{P}$ value $<0.001)$ and in SGRQ components symptom domain had good correlation( $\mathrm{p}=.615 ; \mathrm{P}$ value $<0.001)$ than activity $(\mathrm{P}=.524$, Pvalue $<0.001)$ and impact domain $(\mathrm{P}=.554, \mathrm{P}$ value $<0.001)$.

In Sumithra etal study, BODE index quartiles showed strong correlation with the activity and impact domain of SGRQ score, but showed moderate correlation with the symptom domain, but in this study all the three components ${ }^{2}$ [ symptom $(\mathrm{P}=.937 ; \mathrm{P}$ value <.001) , activity $(\mathrm{P}=.881 ; \mathrm{P}$ value $<0.001)$ and impact $(\mathrm{P}=.928 ; \mathrm{P}$ value $<0.001)$ ] showed strong correlation with BODE index quartile. In this study also higher BODE quartiles were associated with higher (worse) SGRQ scores. The differences among the BODE quartiles in health status indexes were significant for total SGRQ as well as all three of the SGRQ components

Among the individual components of BODE index, the decrease of lung function 
(FEV1\%predicted), and 6MWD, and the increase of MMRC dyspnea grade were associated with corresponding increase in total SGRQ and SGRQ components (symptom, activity, impact). In these components BMI and FEV1\% correlated modestly but 6MWD and mMRC dyspnoea grade correlated strongly with the total SGRQ score.

Several studies report weight loss in COPD subjects possibly due to the increased workload of laboured breathing and under-nutrition due to breathlessness from eating ${ }^{9}$. This in turn reduces both respiratory muscle strength, systemic muscle strength and endurance and participation in social activities. Indeed under-nourished COPD patients might be prone to recurrent infection which may led to increased hospitalisation, reduced exercise capacity and increased mortality. However, in the present study, body mass index had only modest correlation with total SGRQ $\operatorname{score}(\mathrm{P}=.512 ; \mathrm{P}$ value $<0.001)$. In Lin et al. study ${ }^{10}$ also correlation between the BMI and total SGRQ scores was weak. Some authors have found a relationship between low BMI and peripheral muscle impairment and consequently low exercise capacity in individuals with COPD

Main factor for limited daily activities and impaired quality of life in COPD patients were dyspnoea. mMRC scores are found to be responsible for the SGRQ score variance in different studies which showed that dyspnea perception could explain $25 \%$ to $54 \%$ of the quality of life score variance in COPD patients with a strong relationship between SGRQ assessed quality of life and dyspnea perception $^{11,12}$. In this study established a strong correlation between mMRC dyspnoea score and SGRQ score at baseline $(\mathrm{P}=.873 ; \mathrm{P}$ value $<0.001)$. The exercise intolerance was a major factor for influencing quality of life in COPD patients . Similar to other studies, which showed a significant correlation between 6MWT distance and quality of life scores, this study also had a significant correlation between $6 \mathrm{MWD}$ and SGRQ score( SGRQ score increased with 6MWD score $; \mathrm{P}=.731 ; \mathrm{P}$ value $<0.001)$.

\section{Conclusion}

Higher BODE quartile were associated with higher SGRQ scores (worse health status). BMI and $6 \mathrm{mwd}$ showed a significant correlation with health related quality of life.

\section{References}

1. Global Initiative for Chronic Obstructive Lung Disease. Global Strategy for the Diagnosis, Management, and Prevention of Chronic Obstructive Pulmonary Disease. Available from: http://www.goldcopd.com.

2. Sumitra Basuthakur, Sabyasachi Choudhury, Sibes K Das, Anirban Das, Soumya Das, "Evaluation of correlation of BODE index with health-related quality of life among patients with stable COPD attending a tertiary care hospital":Lung India 2015Jan -feb 32(1)24-8

3. Celli BR, Cote CG, Marin JM, et al. The body-mass index, airflow obstruction, dyspnea, and exercise capacity index in chronic obstructive pulmonary disease. The New England Journal of Medicine. 2004;350(10):1005-101[ PubMed]

4. Domingo-Salvany A, Lamarca R, Ferrer $\mathrm{M}$, et al. "Health-related quality of life and mortality in male patients with chronic obstructive pulmonary disease". American Journal of Respiratory and Critical Care Medicine. 2002;166(5):680-685.

5. Ong KC, Earnest A, Lu SJ. A multidimensional grading system (BODE index) as predictor of hospitalization for COPD. Chest. 2005;128(6):3810-3816. [PubMed]

6. Wilson CB ,Jones PW,O'Leary CJ et al.Validation of St George's Respiratory questionnaire in COPD ,Am J Respir Crit Care Med 1997 ; 156:536-41

7. Koblizek V et al ,Salajika F, Cermakova E "Relationship between quality of life and BODE index of stable ex- smokers with COPD” VnitrLek 2009 Oct;55(10):940-7 
8. Antonelli-Incalzi R, Imperiale C, Bellia V, Catalano F, Scichilone N, Pistelli R, et al. Do GOLD stages of COPD severity really correspond to differences in health status? Eur Respir J 2003;22:444

9. Cote CG, Celli BR. "Pulmonary rehabilitation and the BODE index in COPD”. European Respiratory Journal. 2005;26(4):630-636.

10. Lin YX, Xu WN, Liang LR, Pang BS,Nie et al "The cross-sectional and longitudinal association of the BODE index with quality of life in patients with chronic obstructive pulmonary disease"

11. Marin J M et al,Cote CG, Diaz O "Prognostic assessment in COPD :health related quality of life and BODE index" Respir Med 2011Jun;105(6):916-21

12. Medinas -Amoros et al,AlordaC,Renom F "Quality of life in patients with COPD :the predictive validity of BODE index" ChronRespir Dis.2008;5(1):7-11. 